\title{
AMPAR-Independent Effect of Striatal $\alpha$ CaMKII Promotes the Sensitization of Cocaine Reward
}

\author{
Saïd Kourrich, ${ }^{1,2}$ Jason R. Klug, ${ }^{1,2}$ Mark Mayford, ${ }^{3}$ and Mark J. Thomas ${ }^{1,2}$ \\ Departments of ${ }^{1}$ Neuroscience and ${ }^{2}$ Psychology, University of Minnesota, Minneapolis, Minnesota 55455, and ${ }^{3}$ Department of Cell Biology, The Scripps \\ Research Institute, La Jolla, California 92037
}

Changes in CaMKII-regulated synaptic excitability are a means through which experience may modify neuronal function and shape behavior. While behavior in rodent addiction models is linked with CaMKII activity in the nucleus accumbens (NAc) shell, the key cellular adaptations that forge this link are unclear. Using a mouse strain with striatal-specific expression of autonomously active CaMKII (T286D), we demonstrate that while persistent CaMKII activity induces behaviors comparable to those in mice repeatedly exposed to psychostimulants, it is insufficient to increase AMPAR-mediated synaptic strength in NAc shell. However, autonomous CaMKII upregulates A-type $\mathrm{K}^{+}$current (IA) and decreases firing in shell neurons. Importantly, inactivating the transgene with doxycycline eliminates both the IA-mediated firing decrease and the elevated behavioral response to cocaine. This study identifies CaMKII regulation of IA in NAc shell neurons as a novel cellular contributor to the sensitization of cocaine reward.

\section{Introduction}

Information storage in the nervous system is based on changes in cellular excitability in neural circuits. CaMKII, a kinase enriched in the forebrain and postsynaptic density, appears to be a key player in this process (Wayman et al., 2008). A unique feature of this kinase is its autophosphorylation ability, through which it produces an "autonomous" form that is constitutively active well beyond the activating stimulus. Recent studies indicate that autonomous CaMKII in nucleus accumbens (NAc) shell-a region known to control motivation and reward-is linked to addiction-related behavior, such as psychomotor sensitization and increased drug-seeking behavior in animal models (Anderson et al., 2008; Loweth et al., 2008, 2010; Singer et al., 2010). Other studies suggest that these behaviors may be driven by a potentiation of AMPAR function (Pierce et al., 1996; Cornish and Kalivas, 2000; Suto et al., 2004; Kourrich et al., 2007; Conrad et al., 2008; Mameli et al., 2009; Pascoli et al., 2011)—a known consequence of autonomous CaMKII activity. Together, these findings support the possibility that CaMKII-mediated increases in NAc AMPAR function may mediate addiction-related behavior.

\footnotetext{
Received Dec. 21, 2011; revised March 9, 2012; accepted March 22, 2012

Author contributions: S.K., M.M., and M.J.T. designed research; S.K., J.R.K., and M.J.T. performed research; S.K., J.R.K., and M.J.T. analyzed data; S.K. and M.J.T. wrote the paper.

This work was supported by National Institute on Drug Abuse Grant R01 DA019666 (to M.J.T.) and the Whitehall Foundation (to M.J.T.). We thank Drs. Patrick Rothwell, Alfred Robison, and Eric Nestler, and members of Thomas laboratory for helpful comments on a previous version of this manuscript. We also thank Kacey Rajkovich, Bonnie Lacroix, Katie Hottinger, and Greg Cardinal for expert technical assistance.

The authors declare no competing financial interests.

Correspondence should be addressed to Dr. Mark J. Thomas, University of Minnesota, Departments of Neuroscience and Psychology, 6-145 Jackson Hall, 321 Church Street SE, Minneapolis, MN 55455. E-mail: tmhomas@umn.edu.

Saïd Kourrich's present address is National Institute on Drug Abuse/NIH, Cellular Neurobiology Research Branch, Baltimore, MD 21224.

Jason R. Klug's present address is Vanderbilt University, Nashville, TN 37240.

DOI:10.1523/JNEUROSCI.6391-11.2012

Copyright $\odot 2012$ the authors $\quad 0270-6474 / 12 / 326578-09 \$ 15.00 / 0$
}

On the other hand, increases in NAc AMPARs may also suppress behavior in addiction models. For example, viral vector-mediated overexpression of the AMPAR subunit GluA1 in NAc shell decreases cocaine conditioned-place preference (Kelz et al., 1999), promotes extinction (Sutton et al., 2003), and reduces cocaine- and stressinduced reinstatement of cocaine-seeking behavior (Sutton et al., 2003; Bachtell et al., 2008). Thus, in contrast to the emerging consensus that CaMKII promotes addiction-related behaviors, the role of NAc AMPAR function is not yet clear.

To investigate the cellular basis for CaMKII control of addictionrelated behaviors, we used a doxycycline-inducible transgenic mouse strain coding for autonomous CaMKII ( $\alpha$ CaMKII-T286D) specifically in the NAc/striatum (Wiltgen et al., 2007). While other striatal regions may regulate responsiveness to cocaine, we focused our investigation on NAc shell neurons; not only is this subregion intimately related to the expression of motivated behavior (Kelley, 2004), but also because CaMKII in the shell, but not core, increases responsiveness to psychostimulant drugs (Anderson et al., 2008; Loweth et al., 2008, 2010). As expected, T286D mice exhibit sensitized psychomotor and reward responses to cocaine. Surprisingly, rather than CaMKII-induced increased AMPAR function, our study reveals that autonomous CaMKII decreases intrinsic excitability via upregulation of A-type potassium current (IA), and that this firing decrease is tightly linked to behavioral responsiveness to cocaine. This AMPAR-independent function of CaMKII appears to be a novel cellular contributor to the sensitization of cocaine reward.

\section{Materials and Methods \\ Subjects}

The transgenic mice (T286D) used in this experiment have been described previously (Mayford et al., 1996; Wiltgen et al., 2007). Following repeated backcrossing into the $\mathrm{C} 57 \mathrm{BL} / 6$ strain, transgene expression (CaMKII $\alpha$-Asp286) was restricted to the dorsal and ventral striatum/ nucleus accumbens (Wiltgen et al., 2007). For all experiments, mice were group housed and maintained on a $12 \mathrm{~h}$ light/dark cycle. For each exper- 
A

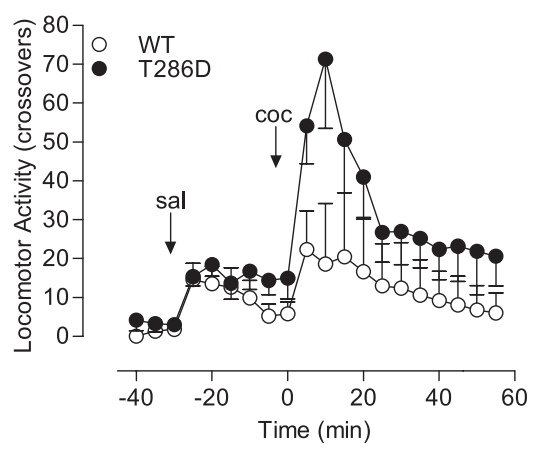

C

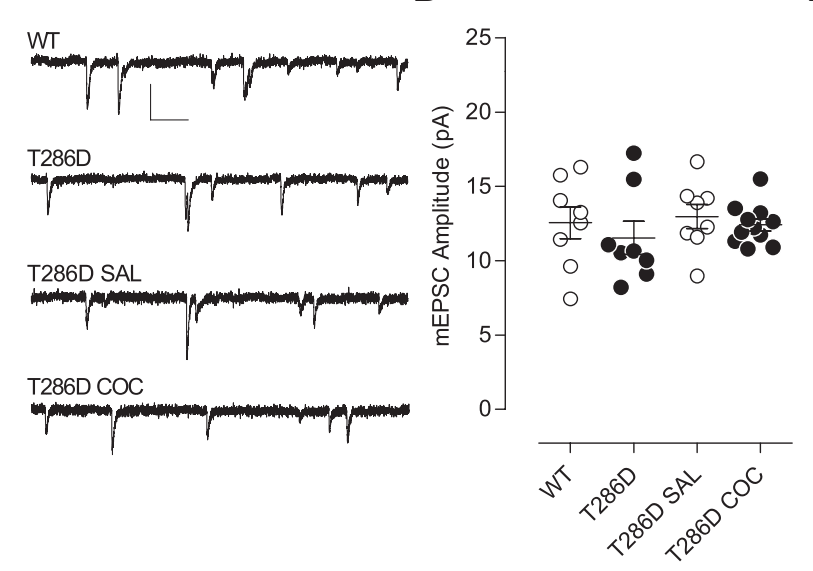

B
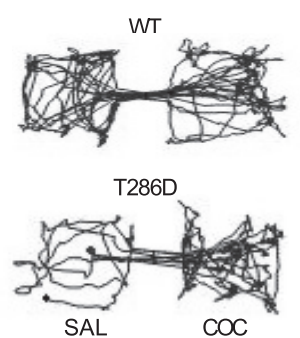

$\operatorname{coc}$

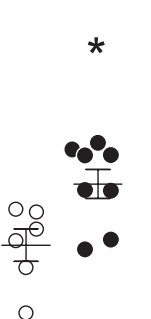

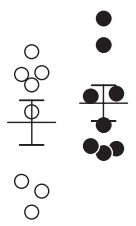

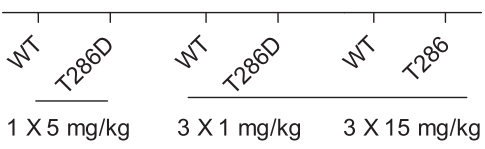

E
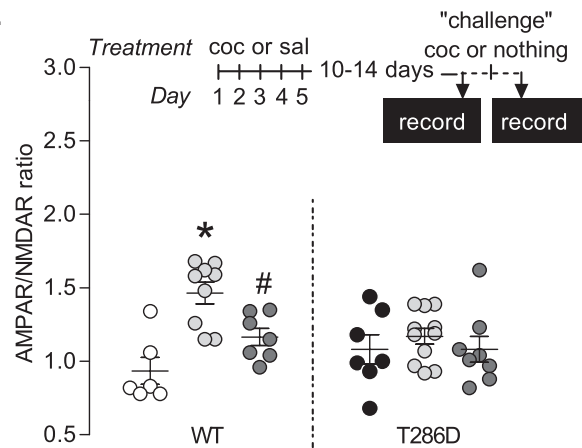

Treatment SAL COC COC $\quad$ SAL COC COC

$\begin{array}{llll:llll}\text { Challenge } & -- & -- & \mathrm{COC} & -- & -- & \mathrm{COC}\end{array}$

Figure 1. AMPAR-mediated synaptic plasticity is dissociated from sensitization in cocaine reward. $\boldsymbol{A}$, An acute injection of cocaine (10 mg/kg) induces an elevated psychomotor effect in T286D $(n=10)$ compared with wild-type (WT, $n=10)$. $\boldsymbol{B}$, Left, Examples of WT and T286D track plots for the first 5 min during the conditioned-place preference (CPP) test day (COC: drug-paired side). Right, 1 or $3 \mathrm{~d}$ of training with 5 and $1 \mathrm{mg} / \mathrm{kg}$ cocaine, respectively, is enough to trigger CPP in T286D, but not WT mice. C, Sample traces of AMPAR-mediated mEPSCs recorded at - $80 \mathrm{mV}$ from WT naive, T286D naive, T286D SAL, and T286D COC, recorded $24 \mathrm{~h}$ after a single saline or cocaine injection. Calibration: $20 \mathrm{~ms}, 20 \mathrm{pA}$. D, No genotype or treatment-related differences were detected in amplitudes of AMPAR-mediated mEPSCs (WT naive, $n=5 ;$ T286D naive, $n=6 ;$ T286 SAL, $n=6$; and T286D COC, $n=8$ ). E, Top, Experimental timeline. Bottom, AMPAR/NMDAR ratio values from neurons in T286D and WT mice treated with saline, cocaine, and challenged with cocaine. Hash marks indicate group means. Error bars indicate SEM. ${ }^{*} p<0.05$.

imental series, groups of T286D or wild-type littermates (7-10 weeks old) were balanced with respect to sex and age. No significant interactions between genotype and sex were detected and thus the results for male and female mice were combined. For transgene inactivation experiments (see Fig. 5), mice in the T286D OFF groups were treated with doxycycline (200 $\mu \mathrm{g} / \mathrm{ml}$ in home-cage water bottles; Wiltgen et al., 2007) starting 2 weeks before behavioral testing.

\section{Behavior}

Locomotion. Mice received either one or five once-daily injections of either cocaine $(15 \mathrm{mg} / \mathrm{kg}$, i.p.) or saline $(0.9 \% \mathrm{NaCl})$. Because T286D mice exhibit elevated basal locomotion, all mice were habituated for $4 \mathrm{~h}$ in activity boxes (Applied Concepts) before injection. The activity boxes consisted of clear plastic cages $(40 \times 20 \times 20 \mathrm{~cm})$ with a central insert $(20 \times 6 \times 20 \mathrm{~cm})$ with ground corncob bedding on the floor. Each cage was placed in a metal frame containing five sets of infrared photobeams, which traversed the short axis of the cage $2.5 \mathrm{~cm}$ above the cage bottom. A computer running custom software (Applied Concepts) monitored the number of "crossovers," defined by successive interruption of beams on opposite ends of the cage. In Figure $1 \mathrm{~A}$, a saline injection was given $30 \mathrm{~min}$ before cocaine injection to test for differences between genotypes in the response to injection in general. Immediately after each injection, horizontal locomotor activity (measured as crossovers) was monitored for $40-60 \mathrm{~min}$.

Place conditioning. Our place conditioning apparatus consisted of a rectangular plastic cage $(40 \times 20 \times 20 \mathrm{~cm})$ divided into two sides by a central partition. Each side had a distinct floor texture: wire mesh versus metal bars. For wall color, mesh was paired with white and metal bars paired with black-and-white stripes ( $3 \mathrm{~d}$ training), or both sides had white walls (single-day training). Body position and movement was monitored by AnyMaze software (Stoelting) via overhead digital cameras. Mice were transported to the testing room and allowed to acclimate for at least $30 \mathrm{~min}$ before every experimental session. Each experiment began with a $20 \mathrm{~min}$ baseline session in which mice were free to move between both sides of the apparatus. Conditioning was conducted over either 1 or $3 \mathrm{~d}$, beginning $24 \mathrm{~h}$ after baseline, with two sessions per day separated by at least $4 \mathrm{~h}$. Each conditioning session consisted of intraperitoneal injection of saline or cocaine $(1,5$, or 15 $\mathrm{mg} / \mathrm{kg}$ ) followed by confinement to the appropriate side for $20 \mathrm{~min}$. For experiments conducted over three training days, the order of sessions (saline/cocaine) was counterbalanced within each day, and cocaine was always paired with the nonpreferred side as determined during the baseline (time spent on nonpreferred side during baseline: $44 \pm 2 \%$ for wild types and $38 \pm 2 \%$ for T286D). By changing to all-white walls, we converted the testing apparatus from biased to unbiased conditions for the single-day training experiment (time spent on drug-paired side during baseline: $49 \pm 4 \%$ for wild types and $50 \pm 6 \%$ for T286D). Thus, in these experiments the side paired with drug was counterbalanced. In all cases, mice exhibiting $>75 \%$ baseline preference for one side were excluded from further study ( 3 of 22 wild types, 1 of 22 T286D). Twenty-four hours after the single or last conditioning session, a 20 min test session was conducted in which mice were free to move between both sides. 
Results are expressed as the difference in time (seconds) spent on the drug-paired side during the test session versus the baseline session (i.e., pre-test vs post-test).

\section{Electrophysiology}

Slice preparation and solutions. Sagittal slices of the NAc shell $(240 \mathrm{~mm})$ were prepared as described previously (Kourrich et al., 2007; Kourrich and Thomas, 2009). Slices recovered in a holding chamber for at least $1 \mathrm{~h}$ before use. During recording they were superfused with $\operatorname{ACSF}\left(22-23^{\circ} \mathrm{C}\right)$ saturated with $95 \% \mathrm{O}_{2} / 5 \%$ $\mathrm{CO}_{2}$ and containing (in $\mathrm{mm}$ ) $119 \mathrm{NaCl}, 2.5$ $\mathrm{KCl}, 1.0 \mathrm{NaH}_{2} \mathrm{PO}_{4}, 1.3 \mathrm{MgSO}_{4} 2.5 \mathrm{CaCl} 2,26.2$ $\mathrm{NaHCO} 3$ and 11 glucose. Picrotoxin $(100 \mu \mathrm{M})$ was added to block $\mathrm{GABA}_{\mathrm{A}}$ receptor-mediated IPSCs. Cells were visualized using IR-DIC optics. Medium spiny neurons were identified by their morphology and high resting membrane potential $(-75$ to $-85 \mathrm{mV})$. We examined shell neurons in medial NAc slices that did not contain dorsal striatal tissue $(\sim 0.44-0.52 \mathrm{~mm}$ lateral). For whole-cell voltage-clamp recordings, we used electrodes (3-5 M $\Omega$ ) containing (in $\mathrm{mm}$ ) 117 cesium gluconate, $2.8 \mathrm{NaCl}, 20$ HEPES, 0.4 EGTA, 5 tetraethylammonium-Cl, 2 MgATP, and 0.3 MgGTP, pH 7.2- 7.4 (285295 mOsm). For whole-cell current-clamp recordings, we used ACSF containing (in addition to picrotoxin), 2 mm kynurenic acid to block glutamate receptors and electrodes (3-5 M $\Omega$ ) containing $120 \mathrm{~K}$-gluconate, $20 \mathrm{KCl}$, 10 HEPES, 0.2 EGTA, $2 \mathrm{Mg} 2 \mathrm{Cl}, 4 \mathrm{Na} 2 \mathrm{ATP}, 0.3$ Tris-GTP.

Synaptic excitability: whole-cell voltageclamp recordings. To assess excitatory synaptic transmission, miniature EPSCs ( $>300$ per cell) were collected in the presence of lidocaine hydrochloride $(0.6-0.8 \mathrm{mM})$ or TTX $(1 \mu \mathrm{M})$; and AMPAR/NMDAR ratios were computed from EPSCs at $+40 \mathrm{mV}$ with or without $50 \mu \mathrm{M}$ D-AP5 as described previously (Thomas et al., 2001). Neurons were voltage clamped at $-80 \mathrm{mV}$ using a Multiclamp 700A amplifier (Molecular Devices). Series resistance (10-30M $\Omega$ ) and input resistance were monitored on-line with a $4 \mathrm{mV}$ depolarizing step (100 ms) given with each afferent stimulus. Data were filtered at $2 \mathrm{kHz}$, digitized at 5 $\mathrm{kHz}$, and collected and analyzed using custom software (Igor Pro; Wavemetrics). Quantal events were analyzed using Minianalysis software (Synaptosoft) with detection parameters set at $>5 \mathrm{pA}$ amplitude and $<3 \mathrm{~ms}$ rise time and verified by eye. NMDAR EPSC decay time constants were calculated from averaged currents (those used to obtain AMPAR/NMDAR ratio) by fitting to double exponential equations. Weighted mean decay time constants were calculated to compare between groups (Rumbaugh and Vicini, 1999). Current-voltage ( $I-V)$ experiment (Fig. $1 D$ ) was performed in the presence of $50 \mu \mathrm{M} \mathrm{D}$-AP-5. Internal solution for $I-V$ experiments contained $0.1 \mathrm{~mm}$ spermine (Fig. 1D). Picrotoxin $(100 \mu \mathrm{M})$ was included in the ACSF to block GABAA receptor-mediated IPSCs.

Intrinsic excitability: whole-cell current-clamp recordings. Data were filtered at $5 \mathrm{kHz}$, digitized at $10 \mathrm{kHz}$, and collected and analyzed using custom software (Igor Pro; Wavemetrics). Membrane potentials were maintained at $-80 \mathrm{mV}$, series resistances $(10-18 \mathrm{M} \Omega$ ) and input resistances were monitored on-line with a $40 \mathrm{pA}$ current injection (150 ms) given before each $800 \mathrm{~ms}$ current injection stimulus. Only cells with a stable $R \mathrm{i}(\Delta<10 \%)$ for the duration of the recording were kept for analysis. To measure "steady-state" voltage responses for each subthreshold pulse in a series of current injections, the voltage values were taken $780 \mathrm{~ms}$ following the onset of each current injection. The value of each parameter for a given cell was the average value measured from 2 to 4 cycles $(800 \mathrm{~ms}$ duration at $0.1 \mathrm{~Hz},-160$ to $+260 \mathrm{pA}$ range with a $20 \mathrm{pA}$
$B$

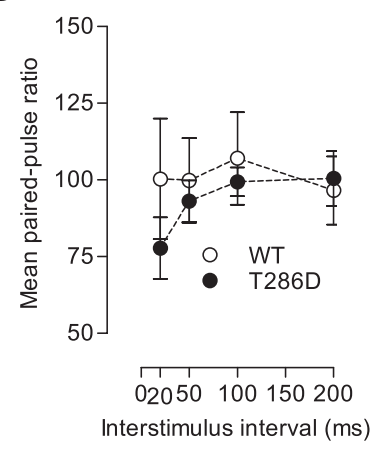

E

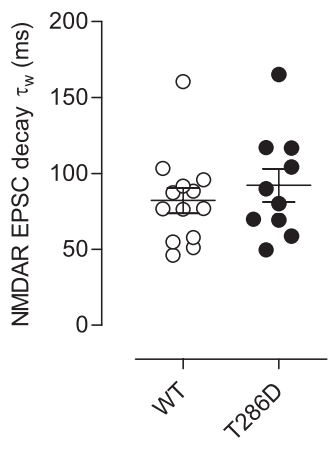

Figure 2. CaMKII transgene does not alter basal synaptic transmission. $A$, Mean values for mEPSC frequency in WT and T286D mice. $\boldsymbol{B}$, Mean paired-pulse ratio values from neurons in WT ( $n=5$ cells) and T286D ( $n=8$ cells) mice are shown for different interstimulus intervals. C, AMPAR/NMDAR ratio values from neurons in WT ( $n=12$ cells) and T286D mice ( $n=10$ cells). $\boldsymbol{D}, I-V$ group). Inset, Examples of evoked AMPA-mediated EPSCs at membrane potentials of $-80 \mathrm{mV}$ and $+40 \mathrm{mV}$ for WT and T286D mice. Calibration: $50 \mathrm{pA}, 40 \mathrm{~ms}$. $\boldsymbol{E}$, Weighted decay time constant $\left(\tau_{\mathrm{w}}\right)$ values of evoked NMDAR EPSCs from WT ( $n=13$ cells) and T286D ( $n=10$ cells) mice. Hash marks indicate group means. Error bars indicate SEM.

step increment). For whole-cell current-clamp recordings, we used ACSF containing picrotoxin $(100 \mu \mathrm{M})$ and $2 \mathrm{~mm}$ kynurenic acid to block $\mathrm{GABA}_{\mathrm{A}}$ and glutamate receptors, respectively.

\section{Statistics}

In $>90 \%$ of experiments, data acquisition and analysis were performed blindly without knowledge of the genotype or treatment of the slices. On $>75 \%$ of recording days, a similar amount of data was collected from both T286D and wild-type groups, or from both saline and cocainetreated. Results are presented as mean \pm SEM. Statistical significance was assessed using two-tailed Student's $t$ tests or 2-way repeated-measures ANOVA and Bonferroni post hoc tests when appropriate.

\section{Results}

AMPAR-mediated synaptic plasticity is dissociated from changes in psychomotor activating and rewarding properties of cocaine

Consistent with previous studies (Anderson et al., 2008; Loweth et al., 2008, 2010), persistent elevation of autonomous CaMKII in NAc shell increases both psychomotor activating (Fig. $1 \mathrm{~A}, 10$ $\mathrm{mg} / \mathrm{kg}$ i.p. cocaine, two-way ANOVA, interaction genotype $\times$ time, $\left.F_{(19,342)}=2.35, p=0.0013\right)$ and rewarding effects of cocaine (Fig. $1 B$, with $5 \mathrm{mg} / \mathrm{kg}, t 9=2.58, p=0.029$, with $1 \mathrm{mg} / \mathrm{kg}$, $t 12=2.80, p=0.016$ and with $15 \mathrm{mg} / \mathrm{kg}, t 14=0.6783, p=$ 0.5086 ). Indeed, even a $1 \mathrm{mg} / \mathrm{kg}$ dose (subthreshold dose for wild types) conditioned T286D mice when training sessions were increased from 1 to $3 \mathrm{~d}$.

One molecular pathway thought to link autonomous CaMKII and addiction-related behaviors is an increase in NAc shell 
AMPAR-mediated transmission (Anderson et al., 2008; Loweth et al., 2010)—a phenomenon also triggered by exposure to repeated in vivo cocaine (Kourrich et al., 2007; Conrad et al., 2008; Mameli et al., 2009). However, in T286D mice, AMPARmediated synaptic function in NAc shell neurons was unaltered. Neither spontaneous miniature AMPAR-mediated EPSCs (Fig. $1 C, D$; amplitude, $p=0.520$; Fig. $2 A$; frequency, $p=0.675$ ) nor AMPAR/NMDAR ratios (ANR) were affected (Fig. $2 C$; $\mathrm{WT}=$ $1.17 \pm 0.17$ and $\mathrm{T} 286 \mathrm{D}=1.13 \pm 0.10 ; p=0.88)$. We also detected no change in the paired-pulse ratio, suggesting that no gross changes in transmitter release probability exist in T286D mice (Fig. $2 B$, two-way ANOVA, genotype effect, $p=0.547$; interaction genotype $\times$ interval, $p=0.251)$. These results may appear unexpected; nevertheless the absence of CaMKII-driven changes in basal AMPAR-mediated synaptic strength is consistent with other studies (Mayford et al., 1995; Bejar et al., 2002) and with the idea that CaMKII has an important initial role in synaptic and behavioral plasticity that dissipates over time (Buard et al., 2010; Loweth et al., 2010).

One important role for persistent autonomous CaMKII may be to reset the threshold necessary for synaptic plasticity induction such that long-term depression is favored (Mayford et al., 1995; Bejar et al., 2002). Interestingly, repeated in vivo cocaine also shifts the plasticity threshold at NAc shell synapses such that cocaine re-exposure induces robust LTD (Kourrich et al., 2007). Thus, a single cocaine injection in T286D mice might be sufficient to produce a synaptic depression. This was not the case (Fig. $1 C, D ; p=0.517)$. Furthermore, while repeated cocaine is known to produce a bidirectional effect on NAc AMPAR synaptic strength depending on the recent history of cocaine exposure (Kourrich et al., 2007), this plasticity is absent in T286D mice (Fig. 1E; WT: one-way ANOVA, $F_{(2,19)}=12.79, p=0.0003$; T286D: one-way ANOVA, $\left.F_{(2,23)}=0.492, p=0.620\right)$. Thus, T286D mice appear to be resistant to cocaine-induced synaptic plasticity in NAc.

CaMKII has the ability to increase the synaptic incorporation of calcium-permeable AMPARs (Hayashi et al., 2000). Interestingly, extended abstinence from repeated cocaine can also induce this process in NAc neurons (Conrad et al., 2008; Mameli et al., 2009) — a condition linked to incubation of cocaine craving (Conrad et al., 2008; Mameli et al., 2009). However, in T286D mice, we detected no changes in AMPAR rectification-a defining characteristic of $\mathrm{Ca}^{2+}$-permeable receptors-suggesting that these receptors have not been incorporated into mutant NAc synapses (Fig. 2D). However, because T286D mice are hyper-responsive to cocaine, perhaps a single cocaine exposure has acquired the capability to trigger a change in the subunit composition of synaptic AMPARs in mutants. This was not the case. At $24 \mathrm{~h}$ postinjection, neither T286D nor wild-type mice showed any change in the rectification index (RI; ratio of peak amplitudes of AMPAR EPSCs recorded at $+40 /-80 \mathrm{mV}$ with $0.1 \mathrm{~mm}$ spermine in the recording pipette solution; one-way ANOVA for RI, $F_{(3,22)}=0.3178, p=0.8124$, $p=0.620$; RI, WT SAL $0.57 \pm 0.08$, WT COC $0.61 \pm 0.05, \mathrm{~T} 286 \mathrm{D}$ SAL $0.58 \pm 0.05$, T286D COC $0.64 \pm 0.09$ ).

In addition to AMPAR changes, repeated cocaine increases the complement of GluN2B-containing NMDARs in NAc neuron synapses (Huang et al., 2009). Since CaMKII phosphorylation also enhances GluN2B function (Liao et al., 2001), we tested for a change in the composition of synaptic NMDARs in T286D mice by measuring evoked NMDA EPSC decay kinetics. We detected no change in this parameter, suggesting a lack of enhancement in GluN2B incorporation in
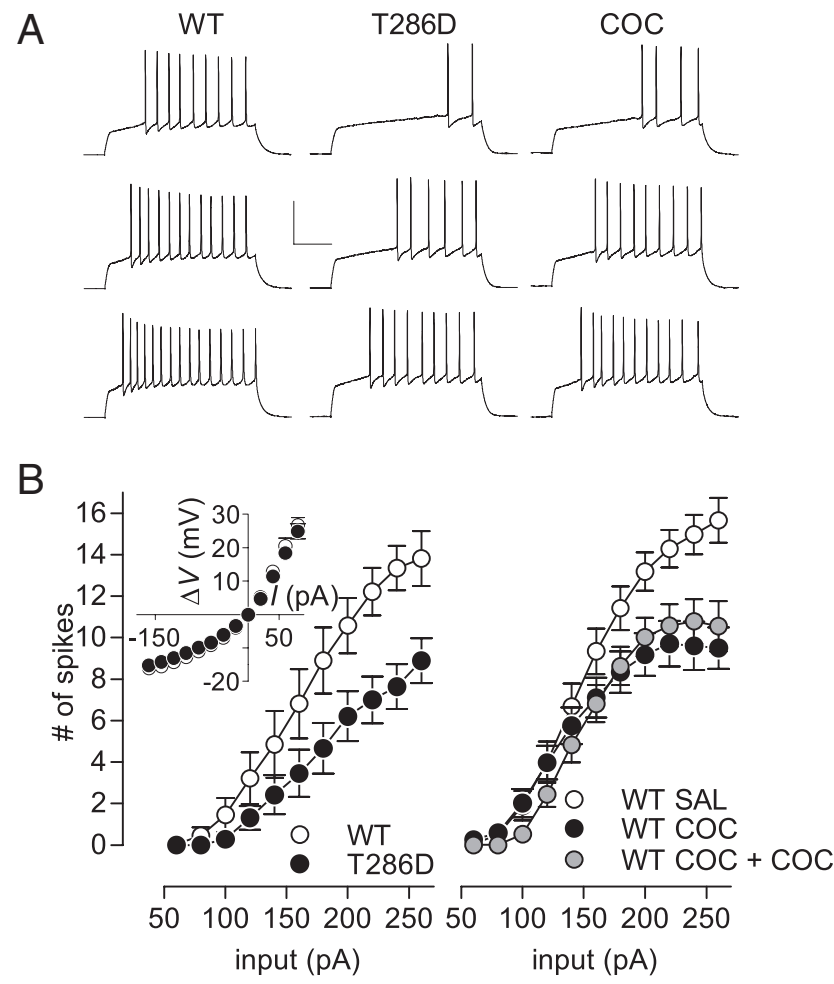

Figure 3. Autonomous CaMKIl and repeated cocaine induce common firing adaptations in NAc shell MSNs. A, Sample traces from WT naive, T286D naive, and cocaine-treated WT (COC) at 160,200 , and 240 pA. $\boldsymbol{B}$, Left, mean number of spikes for a given magnitude of current injection was decreased in T286D mice ( $n=14$ cells) compared with WT littermates ( $n=11$ cells). Inset, No differences in steady-state voltage responses to a series of current pulses were detected between genotypes. Right, mean number of spikes for a given magnitude of current injection was decreased in cocaine-treated ( $C O C, n=22$ cells) compared with saline-treated (SAL, $n=$ 19 cells) animals, an effect that remained unchanged $24 \mathrm{~h}$ after a cocaine challenge injection (15 $\mathrm{mg} / \mathrm{kg}$ i.p.; $\operatorname{COC}+$ COC, $n=19)$. Calibration: $200 \mathrm{~ms}, 50 \mathrm{mV}$. Error bars indicate SEM.

T286D mice (Fig. $2 E$; WT, $\tau \mathrm{W}=82.1 \pm 8.2, n=13$; T286D, $\tau \mathrm{W}=92.1 \pm 11.0, n=10, p=0.50)$.

\section{Both CaMKII and repeated cocaine decrease firing rate through IA upregulation}

While CaMKII-induced changes in NAc AMPAR or NMDAR function may be involved in induction of psychomotor sensitization to cocaine, these changes do not seem necessary for its expression. Another, perhaps less appreciated, function of autonomous CaMKII is to decrease intrinsic excitability via changes in voltage-dependent $\mathrm{K}^{+}$channels (Varga et al., 2004; Sergeant et al., 2005). Indeed, NAc shell MSNs in T286D mice exhibit decreased firing capability compared with wild types (two-way ANOVA, interaction genotype $\times$ input, $F_{(10,230)}=$ $3.41, p=0.0003$, genotype effect, $\left.F_{(1,23)}=8.12, p=0.0091\right)$. This electrophysiological phenotype recapitulates the decreased firing rate observed in cocaine-treated wild types-an effect that endures despite weeks of drug abstinence and following cocaine re-exposure (two-way ANOVA, interaction treatment $\times$ input, $F_{(20,570)}=4.35, p<0.0001$, treatment effect, $F_{(2,57)}=4.21, p=$ 0.0197; Fig. 3; Kourrich and Thomas, 2009).

Interestingly, the pattern of changes in spike train parameters in T286D mice is identical to that observed in cocaine-treated wild types. The first spike latency is increased $(t 21=2.119, p=$ $0.046)$, the train duration is decreased $(t 21=3.393, p=0.0027)$ and the interspike interval (ISI) is increased $(t 21=2.853, p=$ 0.0095; Fig. 4A-C; Kourrich and Thomas, 2009). These changes 
A

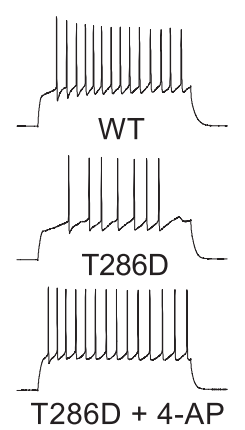

B

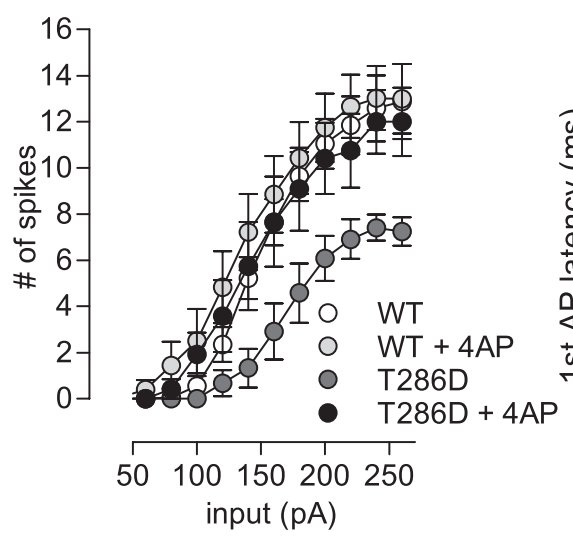

C

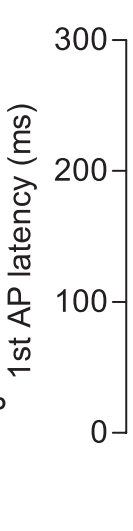

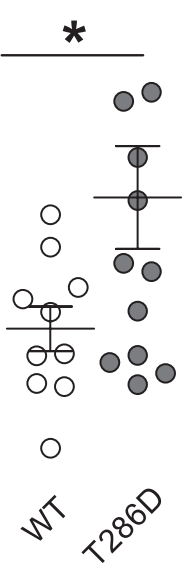

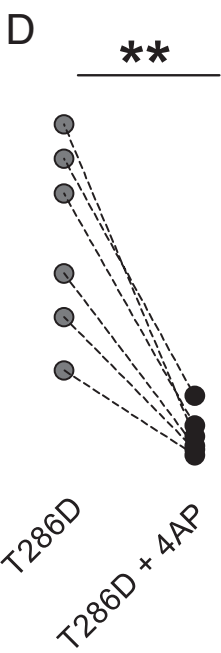

Figure 4. The firing rate depression induced by autonomous CaMKII in NAc shell MSNs is mediated by increased A-Type $\mathrm{K}^{+}$Current. $A$, Sample traces from WT, T286, and T286D $+4 \mathrm{AP}$ at 240 pA. $\boldsymbol{B}, 4 \mathrm{AP}(100 \mu \mathrm{M})$ readjusts the firing capacity in T286D mice without affecting firing rate in WT (WT, $n=10 ; \mathrm{WT}+4 \mathrm{AP}, n=10 ; \mathrm{T} 286 \mathrm{D}, n=6 ; \mathrm{T} 286 \mathrm{D}+4 \mathrm{AP}, n=6)$. C, Latency to the first spike at $240 \mathrm{pA}(\mathrm{WT}, n=10 ; \mathrm{T286D}, n=11)$. D, Latency to the first spike before and during 4AP application at $240 \mathrm{pA}$ in T286D mice $(n=6)$. Hash marks indicate group means. Calibration: $200 \mathrm{~ms}, 50$ $\mathrm{mV}$. Error bars indicate SEM. ${ }^{*} p<0.05$.

are consistent with an increase in transient A-type $\mathrm{K}^{+}$current (IA) in striatal neurons (Nisenbaum et al., 1994; Kourrich and Thomas, 2009). Thus, we first investigated a potential role for IA by using a dose of 4 -aminopyridine (4AP; $100 \mu \mathrm{M}$ ) that selectively blocks this current (Bargas et al., 1989; Nisenbaum et al., 1994). While IA blockade by 4AP does not affect firing rate in wild types (WT vs WT + 4AP: two-way ANOVA, interaction treatment $\times$ input, $F_{(11,198)}=0.6454, p=0.7883$, treatment effect, $F_{(1,18)}=$ 0.5705, $p=0.4598$; Fig. $4 B$, and Kourrich and Thomas, 2009), $4 \mathrm{AP}$ normalizes firing in $\mathrm{T} 286 \mathrm{D}$ to the level normally seen in wild types (Fig. $4 B$, T286D + 4AP vs WT: two-way ANOVA, interaction genotype $\times 4 \mathrm{AP}, F_{(11,154)}=0.5162, p=0.8903$, treatment effect, $\left.F_{(1,14)}=0.0003, p=0.9871\right)$.

Does $4 \mathrm{AP}$ readjust the firing capacity through a simple increase in overall excitability, or a specific effect on IA? Given that delayed spiking in T286D cells (Fig. 4C), a factor that plays a key role in their depressed firing capacity, is readjusted to a low level with $4 \mathrm{AP}$ (Fig. $4 D$; paired $t$ test, $t 5=5.84, p=0.0021$ ) and that this effect is not observed with the broad-spectrum potassium channel blocker TEA (Bargas et al., 1989), the renormalization of firing capacity by $4 \mathrm{AP}$ is not likely due to simple increases in overall excitability, but to specific IA blockade.

\section{Psychomotor sensitization and firing rate depression are occluded in T286D mice but rescued when the transgene is inactivated}

CaMKII activity in the NAc shell appears to be an important factor underlying expression of psychomotor sensitization (Pierce et al., 1998; Loweth et al., 2008, 2010). Concordant with this, we found that T286D mice-which exhibit a "sensitized" locomotor response to a single dose (Fig. $1 A$ ) - did not exhibit further increases in response to multiple additional injections (two-way ANOVA, interaction treatment $\times$ day, $F_{(4,32)}=0.0474, p=$ 0.9955 ; Fig. $5 A$ ), suggesting that sensitization was occluded by autonomous CaMKII in mutants. Interestingly, the IA-linked firing decrease seen in wild-type shell MSNs after repeated psychostimulants (Kourrich and Thomas, 2009) was also occluded in T286D mice (Fig. 5B, C; two-way ANOVA, interaction treatment $\times$ input, $F_{(10,363)}=0.416, p=0.939$; treatment effect, $\left.F_{(1,10)}=0.3714, p=0.543\right)$. This dual occlusion of typical behav- ioral and physiological responses to repeated cocaine in T286D mice suggests that decreased firing capability in NAc shell MSNs plays an important role in the expression of psychomotor sensitization to cocaine.

To further examine the inter-relationships between decreased shell MSNs firing, persistent autonomous CaMKII and behavioral responsiveness to cocaine, we prevented transgene activation in T286D mice through doxycycline (DOX) treatment (Wiltgen et al., 2007). NAc shell MSNs from DOX-treated T286D mice exhibited spiking rates similar to wild types (Fig. $5 D, E$; two-way ANOVA, interaction treatment $X$ input, $F_{(6,84)}=12.24$, $p<0.0001$; treatment effect, $\left.F_{(1,14)}=11.84, p=0.0040\right)$, and normalization of $I$ A-controlled parameters (increase in first spike latency: $t 14=2.301, p=0.037$; decrease in interspike interval: $t 14=2.945, p=0.011$; Fig. $5 F$ ). In addition, DOX treatment re-established the capability for sensitization following repeated cocaine in T286D mice (Fig. 5G; two-way ANOVA, interaction treatment $\times$ day, $\left.F_{(1,42)}=15.62, p=0.0003\right)$. Interestingly, although transgene inactivation re-established both the capability to sensitize (Fig. 5G) and raised the MSN firing rate (Fig. 5F), the elevated basal locomotion was not normalized (see Materials and Methods, Locomotion; compare WT SAL in Fig. 5A and T286D OFF SAL in Fig. 5G). This is important because it dissociates the elevated basal locomotion in T286D mice- of unknown origin and significance-from the cocaine sensitization phenotype described here. These data further support the idea that widespread CaMKII-mediated decreases in shell MSN excitability may be an important factor in the expression of cocaine sensitization.

\section{Discussion}

This study reveals an AMPAR-independent function of CaMKII in the sensitization of cocaine reward; negative modulation of intrinsic excitability. Specifically, autonomous CaMKII decreases firing capacity in NAc shell MSNs through IA upregulation without observable changes in excitatory synaptic transmission, and this firing plasticity is linked to cocaine sensitization. These data raise two important points. First, although repeated cocaine exposure produces robust potentiation of AMPAR function in NAc shell MSNs during abstinence (Kourrich et al., 2007; Conrad et al., 2008; Mameli et al., 2009; Pascoli et al., 2011), our data suggest 
A

B

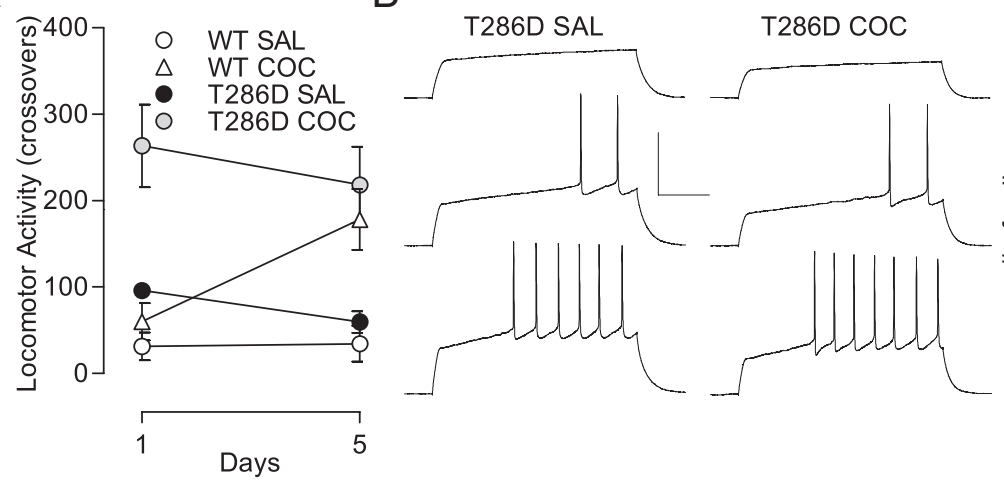

C

D
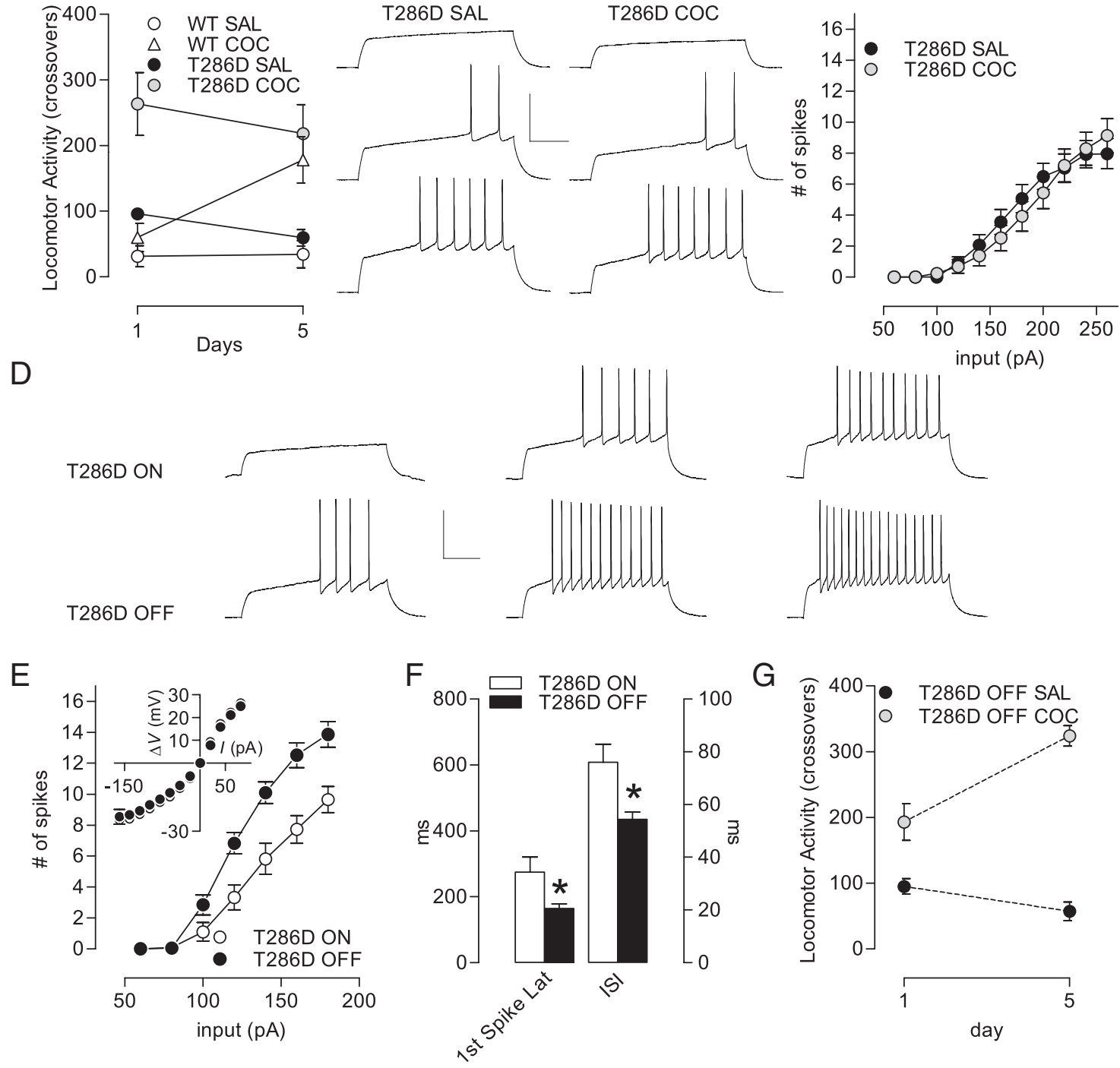

Figure 5. Psychomotor sensitization and firing rate depression are occluded in T286D mice but rescued upon transgene inactivation. $\boldsymbol{A}$, Psychomotor sensitization to cocaine is absent in T286D mice (WT SAL, $n=4 ;$ T286D SAL, $n=4 ;$ WT COC, $n=6 ;$ T286D COC, $n=6$ ). B, Sample traces from T286D SAL and T286D COC at 120, 160, and 200 pA. C, A sensitizing regimen of cocaine (5 $\times 15$ $\mathrm{mg} / \mathrm{kg}$ ) does not further decrease the firing rate depression in T286D mice (SAL, $n=14 ; C O C, n=21$ ). D, Sample traces from T286D 0N (transgene turned on) and T286D 0FF (transgene turned off) at 100,140 , and $180 \mathrm{pA}$. $\boldsymbol{E}$, Turning the transgene $0 \mathrm{FF}$ re-establishes a normal firing rate. Inset, no differences in steady-state voltage responses to a series of current pulses between T286 $0 \mathrm{~N}$ ( $n=$ 9) and T286 OFF $(n=8)$. $F$, Turning the transgene OFF readjusts the A-type $\mathrm{K}^{+}$current-regulated intrinsic excitability parameters, the latency to the first spike and interspike interval (at $160 \mathrm{pA}$; T286D 0N, $n=9$ cells; T286 OFF, $n=8$ cells). G, Turning the transgene OFF rescues the psychomotor sensitization phenotype (T286D 0FF SAL, $n=9$; T286 0FF COC, $n=14$ ). Calibration: 200 ms, $50 \mathrm{mV}$. Error bars indicate SEM. ${ }^{*} p<0.05$.

that widespread AMPAR potentiation is not necessary for the expression of cocaine reward sensitization. This conclusion is consistent with data from other recent studies using biochemical and viral approaches (Bachtell and Self, 2008; Ferrario et al., 2010). Second, the electrophysiological phenotype of NAc shell neurons in T286D mice recapitulates the state of these neurons in animals treated with chronic cocaine. This includes the upregulation of IA (Kourrich and Thomas, 2009) and decrease in firing capacity (Ishikawa et al., 2009; Kourrich and Thomas, 2009) as well as the lack of AMPAR potentiation in early drug withdrawal (1-3 d; Kourrich et al., 2007). Because autonomous CaMKII in NAc shell can control behavioral responsiveness to cocaine (Anderson et al., 2008; Loweth et al., 2008, 2010) as well as recapitulate cocaine's effect of reduced excitability, the picture is emerging that not only is IA upregulation in NAc shell neurons a putative mediator for sensitization of cocaine reward, but that this effect may be induced by autonomous CaMKII.
In vivo psychostimulant exposure enhances levels of autonomous CaMKII in the NAc, particularly in the shell subregion (Anderson et al., 2008; Boudreau et al., 2009; Loweth et al., 2010). Based on the known role for CaMKII activity in promoting AMPAR delivery to synapses (Hayashi et al., 2000) and the psychostimulant-triggered phosphorylation of NAc AMPAR subunits at CaMKII sites (Anderson et al., 2008; Loweth et al., 2010), a link between in vivo psychostimulant-induced CaMKII activity and AMPAR potentiation in NAc is a strong possibility. On the other hand, although autonomous CaMKII is clearly sufficient to produce a rapid increase in AMPAR synaptic strength (Lledo et al., 1995), previous studies testing the electrophysiological effects of persistent autonomous CaMKII (days to weeks) reported no change in basal synaptic transmission (Mayford et al., 1995; Bejar et al., 2002), consistent with our results. Interestingly, in these studies, persistent autonomous CaMKII shifted the stimulation threshold for synaptic plasticity in favor of the induction of 
long-term depression (LTD) over long-term potentiation-a phenomenon similar to that observed in abstinence from repeated cocaine if cocaine re-exposure is used as the plasticity induction stimulus (Kourrich et al., 2007). Surprisingly, not only did NAc MSNs in T286D mice lack a shift toward experience-driven LTD, they exhibited no plasticity in AMPAR synaptic strength under any type of drug experience. This rigidity of synaptic transmission in T286D mice is reminiscent of the recently discovered long-lasting resistance to experimenter-induced plasticity in NAc following chronic cocaine that occurred strictly in animals with multiple behavioral abnormalities that characterize addiction (Kasanetz et al., 2010). This "anaplasticity" has been proposed as a deleterious neural adaptation contributing to the transition to addiction.

In addition to synaptic changes in NAc MSNs, passive and active exposure to cocaine is known to decrease intrinsic excitability (Ishikawa et al., 2009; Kourrich and Thomas, 2009; $\mathrm{Mu}$ et al., 2010). Although repeated cocaine is known to modulate $\mathrm{K}^{+}, \mathrm{Na}^{+}$and $\mathrm{Ca}^{2+}$ ionic conductances (Kalivas and $\mathrm{Hu}$, 2006), recent studies indicate a particularly important role for $\mathrm{K}^{+}$currents in controlling both drug-induced changes in NAc MSN excitability (Ishikawa et al., 2009; Kourrich and Thomas, 2009) and locomotor responsiveness to cocaine (Dong et al., 2006). Downregulation in activity of the transcription factor, CREB, is a likely contributor to these changes (Dong et al., 2006). Interestingly, CaMKII phosphorylates CREB at Ser142, reducing its transcriptional activity (Sun et al., 1994; Wu and McMurray, 2001) — an effect recently shown to occur in NAc shell (Loweth et al., 2010). Thus, an antagonistic relationship between CaMKII and CREB activity may explain the similarity between the behavioral phenotype in the T286D mice described here and rats overexpressing a dominant-negative mutant CREB in NAc shell (Carlezon et al., 1998).

Which types of $\mathrm{K}^{+}$currents are involved? While blockade of the small conductance $\mathrm{KCa}$ channel partially restores firing capacity in NAc MSNs following repeated cocaine (Ishikawa et al., 2009), IA blockade appears to fully restore both the NAc shell MSNs firing capacity and to "correct" the firing pattern (Kourrich and Thomas, 2009). These data indicate that although other targets are involved in cocaine-induced decrease in firing capability, IA appears to play a major role. While not as extensively studied as its role in AMPAR modulation, CaMKII activity is reported to increase IA current (Varga et al., 2004; Sergeant et al., 2005), leading to a decrease in firing capacity (Varga et al., 2004). The depressed firing rate exhibited by T286D mice appears to occur through this mechanism.

Importantly, our data provide several pieces of evidence that autonomous CaMKII decreases NAc shell excitability by the same mechanism as repeated cocaine. First, pharmacological blockade of IA normalizes the firing decrease produced by repeated cocaine (Kourrich and Thomas, 2009) and in T286D mice. Second, changes in the pattern of spiking - first spike latency, train duration and interspike interval-in cocaine-treated wild types and T286D mice are indistinguishable. Third, the cocaine-induced firing decrease in wild types is occluded in T286D mice. Furthermore, the relationship between decreased NAc shell excitability and cocaine sensitization is supported by the fact that nullifying T286D transgene expression with doxycycline re-established a typical shell MSN firing capacity and spiking pattern as well as the capability for psychomotor sensitization following repeated cocaine.

The question of which $\mathrm{K}^{+}$channel subunits are responsible for an increase in IA is unresolved. The number of combinations of voltage-gated $\mathrm{K}^{+}$channel subtypes (e.g., Kv1-4.x) that can produce IA is quite large. For example, while the pore-forming $\alpha$-subunits from $\mathrm{Kv} 4$ subfamily represent a major contributor, association of Kv1 subfamily members with $\mathrm{Kv} \beta 1$ auxiliary subunits also leads to IA (Rettig et al., 1994; Leicher et al., 1998; Birnbaum et al., 2004). The strongest candidate contributor to the increase in IA demonstrated here is the Kv4.2 subunit, as it is densely expressed in striatum and underlies most IA in striatal MSNs (Varga et al., 2000; Vacher et al., 2006). In addition, Varga et al. (2004) demonstrated that CaMKII regulates Kv4.2 in hippocampal neurons and cultured cells, resulting in a functional increase in IA and a decrease in excitability, similar to what we observed here.

Combined with previous studies (Kourrich et al., 2007; Ishikawa et al., 2009; Kourrich and Thomas, 2009), our findings suggest an interplay between accumbens synaptic and intrinsic plasticity in the long-lasting vulnerability to sensitization of cocaine reward. While the nature of this interaction is still unclear, we propose that cocaine-induced, widespread AMPAR potentiation in shell MSNs (Kourrich et al., 2007) may serve to counteract a deleterious adaptation, persistent IA-mediated decreases in firing capacity. Thus, a general reversal of AMPAR potentiation resulting from drug reexposure (Kourrich et al., 2007) or stress (Rothwell et al., 2011) - experiences that can reinitiate drug seeking in human addicts and animal models (Stewart, 2004) — may open a gateway facilitating drug-seeking behavior. Indeed, global shell MSN hypoactivity has been likened to releasing a "brake" on appetitive reward-seeking behaviors (Kelley, 2004; Taha and Fields, 2006; Ambroggi et al., 2011) that initiates and maintains feeding behavior (Krause et al., 2010), and is possibly even involved in encoding the positive hedonic value of a stimulus (Carlezon and Thomas, 2009).

Interestingly, recent findings indicate that AMPAR potentiation in synaptic subcircuits of NAc shell, including prefrontal inputs to D1-containing MSNs, may be necessary for psychomotor sensitization (Pascoli et al., 2011). The apparent importance of both a potentiated subcircuit and a general decrease in shell MSN excitability (present data) for sensitization is intriguing. This situation is analogous to the differential inhibition of "signal" versus "background" activity known to develop in NAc neurons in chronic cocaine- and nicotine-self-administering animals (Peoples and Cavanaugh, 2003; Peoples et al., 2004, 2007b; Guillem and Peoples, 2010, 2011). Furthermore, the magnitude of the activity differential between "task-active" versus "tasknonactive" neurons in an individual animal correlates with its propensity for drug-seeking behavior (Peoples et al., 2007b). Thus, the IA-mediated decrease in NAc shell MSN described here is an appealing candidate mechanism for the inhibition component of the "differential inhibition hypothesis" for cocaine addiction posited by Peoples and colleagues (Peoples et al., 2007a).

Plasticity in intrinsic excitability is emerging as an integral contributor to pathological neural function in models of multiple CNS disorders including Alzheimer's Disease, neuropathic pain and epilepsy (Beck and Yaari, 2008). Interestingly, evidence is mounting that plasticity in Kv4.2-mediated IA may be a common culprit across these disorders. Our present findings implicating IA in a model for the neurobiology of addiction further indicates the need for continued investigation of this ubiquitous and intriguing modulator of neuronal excitability. 


\section{References}

Ambroggi F, Ghazizadeh A, Nicola SM, Fields HL (2011) Roles of nucleus accumbens core and shell in incentive-cue responding and behavioral inhibition. J Neurosci 31:6820-6830.

Anderson SM, Famous KR, Sadri-Vakili G, Kumaresan V, Schmidt HD, Bass CE, Terwilliger EF, Cha JH, Pierce RC (2008) CaMKII: a biochemical bridge linking accumbens dopamine and glutamate systems in cocaine seeking. Nat Neurosci 11:344-353.

Bachtell RK, Self DW (2008) Renewed cocaine exposure produces transient alterations in nucleus accumbens AMPA receptor-mediated behavior. J Neurosci 28:12808-12814.

Bachtell RK, Choi KH, Simmons DL, Falcon E, Monteggia LM, Neve RL, Self DW (2008) Role of GluR1 expression in nucleus accumbens neurons in cocaine sensitization and cocaine-seeking behavior. Eur J Neurosci 27:2229-2240.

Bargas J, Galarraga E, Aceves J (1989) An early outward conductance modulates the firing latency and frequency of neostriatal neurons of the rat brain. Exp Brain Res 75:146-156.

Beck H, Yaari Y (2008) Plasticity of intrinsic neuronal properties in CNS disorders. Nat Rev Neurosci 9:357-369.

Bejar R, Yasuda R, Krugers H, Hood K, Mayford M (2002) Transgenic calmodulin-dependent protein kinase II activation: dose-dependent effects on synaptic plasticity, learning, and memory. J Neurosci 22:5719-5726.

Birnbaum SG, Varga AW, Yuan LL, Anderson AE, Sweatt JD, Schrader LA (2004) Structure and function of Kv4-family transient potassium channels. Physiol Rev 84:803-833.

Boudreau AC, Ferrario CR, Glucksman MJ, Wolf ME (2009) Signaling pathway adaptations and novel protein kinase A substrates related to behavioral sensitization to cocaine. J Neurochem 110:363-377.

Buard I, Coultrap SJ, Freund RK, Lee YS, Dell'Acqua ML, Silva AJ, Bayer KU (2010) CaMKII "autonomy" is required for initiating but not for maintaining neuronal long-term information storage. J Neurosci 30:8214-8220.

Carlezon WA Jr, Thome J, Olson VG, Lane-Ladd SB, Brodkin ES, Hiroi N, Duman RS, Neve RL, Nestler EJ (1998) Regulation of cocaine reward by CREB. Science 282:2272-2275.

Carlezon WA Jr, Thomas MJ (2009) Biological substrates of reward and aversion: a nucleus accumbens activity hypothesis. Neuropharmacology 56 [Suppl 1]:122-132.

Conrad KL, Tseng KY, Uejima JL, Reimers JM, Heng LJ, Shaham Y, Marinelli M, Wolf ME (2008) Formation of accumbens GluR2-lacking AMPA receptors mediates incubation of cocaine craving. Nature 454:118-121.

Cornish JL, Kalivas PW (2000) Glutamate transmission in the nucleus accumbens mediates relapse in cocaine addiction. J Neurosci 20:RC89.

Dong Y, Green T, Saal D, Marie H, Neve R, Nestler EJ, Malenka RC (2006) CREB modulates excitability of nucleus accumbens neurons. Nat Neurosci 9:475-477.

Ferrario CR, Li X, Wang X, Reimers JM, Uejima JL, Wolf ME (2010) The role of glutamate receptor redistribution in locomotor sensitization to cocaine. Neuropsychopharmacology 35:818-833.

Guillem K, Peoples LL (2010) Progressive and lasting amplification of accumbal nicotine-seeking neural signals. J Neurosci 30:276-286.

Guillem K, Peoples LL (2011) Acute effects of nicotine amplify accumbal neural responses during nicotine-taking behavior and nicotine-paired environmental cues. PloS one 6:e24049.

Hayashi Y, Shi SH, Esteban JA, Piccini A, Poncer JC, Malinow R (2000) Driving AMPA receptors into synapses by LTP and CaMKII: requirement for GluR1 and PDZ domain interaction. Science 287:2262-2267.

Huang YH, Lin Y, Mu P, Lee BR, Brown TE, Wayman G, Marie H, Liu W, Yan Z, Sorg BA, Schlüter OM, Zukin RS, Dong Y (2009) In vivo cocaine experience generates silent synapses. Neuron 63:40-47.

Ishikawa M, Mu P, Moyer JT, Wolf JA, Quock RM, Davies NM, Hu XT, Schlüter OM, Dong Y (2009) Homeostatic synapse-driven membrane plasticity in nucleus accumbens neurons. J Neurosci 29:5820-5831.

Kalivas PW, Hu XT (2006) Exciting inhibition in psychostimulant addiction. Trends Neurosci 29:610-616.

Kasanetz F, Deroche-Gamonet V, Berson N, Balado E, Lafourcade M, Manzoni O, Piazza PV (2010) Transition to addiction is associated with a persistent impairment in synaptic plasticity. Science 328:1709-1712.

Kelley AE (2004) Memory and addiction: shared neural circuitry and molecular mechanisms. Neuron 44:161-179.
Kelz MB, Chen J, Carlezon WA Jr, Whisler K, Gilden L, Beckmann AM, Steffen C, Zhang YJ, Marotti L, Self DW, Tkatch T, Baranauskas G, Surmeier DJ, Neve RL, Duman RS, Picciotto MR, Nestler EJ (1999) Expression of the transcription factor deltaFosB in the brain controls sensitivity to cocaine. Nature 401:272-276.

Kourrich S, Thomas MJ (2009) Similar neurons, opposite adaptations: psychostimulant experience differentially alters firing properties in accumbens core versus shell. J Neurosci 29:12275-12283.

Kourrich S, Rothwell PE, Klug JR, Thomas MJ (2007) Cocaine experience controls bidirectional synaptic plasticity in the nucleus accumbens. J Neurosci 27:7921-7928.

Krause M, German PW, Taha SA, Fields HL (2010) A pause in nucleus accumbens neuron firing is required to initiate and maintain feeding. J Neurosci 30:4746-4756.

Leicher T, Bähring R, Isbrandt D, Pongs O (1998) Coexpression of the KCNA3B gene product with Kv1.5 leads to a novel A-type potassium channel. J Biol Chem 273:35095-35101.

Liao D, Scannevin RH, Huganir R (2001) Activation of silent synapses by rapid activity-dependent synaptic recruitment of AMPA receptors. J Neurosci 21:6008-6017.

Lledo PM, Hjelmstad GO, Mukherji S, Soderling TR, Malenka RC, Nicoll RA (1995) Calcium/calmodulin-dependent kinase II and long-term potentiation enhance synaptic transmission by the same mechanism. Proc Natl Acad Sci U S A 92:11175-11179.

Loweth JA, Baker LK, Guptaa T, Guillory AM, Vezina P (2008) Inhibition of CaMKII in the nucleus accumbens shell decreases enhanced amphetamine intake in sensitized rats. Neurosci Lett 444:157-160.

Loweth JA, Singer BF, Baker LK, Wilke G, Inamine H, Bubula N, Alexander JK, Carlezon WA Jr, Neve RL, Vezina P (2010) Transient overexpression of alpha-Ca2+/calmodulin-dependent protein kinase II in the nucleus accumbens shell enhances behavioral responding to amphetamine. J Neurosci 30:939-949.

Mameli M, Halbout B, Creton C, Engblom D, Parkitna JR, Spanagel R, Lüscher C (2009) Cocaine-evoked synaptic plasticity: persistence in the VTA triggers adaptations in the NAc. Nat Neurosci 12:1036-1041.

Mayford M, Wang J, Kandel ER, O’Dell TJ (1995) CaMKII regulates the frequency-response function of hippocampal synapses for the production of both LTD and LTP. Cell 81:891-904.

Mayford M, Bach ME, Huang YY, Wang L, Hawkins RD, Kandel ER (1996) Control of memory formation through regulated expression of a CaMKII transgene. Science 274:1678-1683.

Mu P, Moyer JT, Ishikawa M, Zhang Y, Panksepp J, Sorg BA, Schlüter OM, Dong Y (2010) Exposure to cocaine dynamically regulates the intrinsic membrane excitability of nucleus accumbens neurons. J Neurosci 30:3689-3699.

Nisenbaum ES, Xu ZC, Wilson CJ (1994) Contribution of a slowly inactivating potassium current to the transition to firing of neostriatal spiny projection neurons. J Neurophysiol 71:1174-1189.

PascoliV, Turiault M, Lüscher C (2012) Reversal of cocaine-evoked synaptic potentiation resets drug-induced adaptive behaviour. Nature 481:71-75.

Peoples LL, Cavanaugh D (2003) Differential changes in signal and background firing of accumbal neurons during cocaine self-administration. J Neurophysiol 90:993-1010.

Peoples LL, Lynch KG, Lesnock J, Gangadhar N (2004) Accumbal neural responses during the initiation and maintenance of intravenous cocaine self-administration. J Neurophysiol 91:314-323.

Peoples LL, Kravitz AV, Guillem K (2007a) The role of accumbal hypoactivity in cocaine addiction. ScientificWorldJournal 7:22-45.

Peoples LL, Kravitz AV, Lynch KG, Cavanaugh DJ (2007b) Accumbal neurons that are activated during cocaine self-administration are spared from inhibitory effects of repeated cocaine self-administration. Neuropsychopharmacology 32:1141-1158.

Pierce RC, Bell K, Duffy P, Kalivas PW (1996) Repeated cocaine augments excitatory amino acid transmission in the nucleus accumbens only in rats having developed behavioral sensitization. J Neurosci 16:1550-1560.

Pierce RC, Quick EA, Reeder DC, Morgan ZR, Kalivas PW (1998) Calciummediated second messengers modulate the expression of behavioral sensitization to cocaine. J Pharmacol Exp Ther 286:1171-1176.

Rettig J, Heinemann SH, Wunder F, Lorra C, Parcej DN, Dolly JO, Pongs O (1994) Inactivation properties of voltage-gated $\mathrm{K}+$ channels altered by presence of beta-subunit. Nature 369:289-294.

Rothwell PE, Kourrich S, Thomas MJ (2011) Synaptic adaptations in the 
nucleus accumbens caused by experiences linked to relapse. Biological psychiatry 69:1124-1126.

Rumbaugh G, Vicini S (1999) Distinct synaptic and extrasynaptic NMDA receptors in developing cerebellar granule neurons. J Neurosci 19:1060310610.

Sergeant GP, Ohya S, Reihill JA, Perrino BA, Amberg GC, Imaizumi Y, Horowitz B, Sanders KM, Koh SD (2005) Regulation of Kv4.3 currents by $\mathrm{Ca} 2+/$ calmodulin-dependent protein kinase II. Am J Physiol Cell Physiol 288:C304-C313.

Singer BF, Loweth JA, Neve RL, Vezina P (2010) Transient viral-mediated overexpression of alpha-calcium/calmodulin-dependent protein kinase II in the nucleus accumbens shell leads to long-lasting functional upregulation of alpha-amino-3-hydroxyl-5-methyl-4-isoxazole-propionate receptors: dopamine type-1 receptor and protein kinase A dependence. Eur J Neurosci 31:1243-1251.

Stewart J (2004) Pathways to relapse: factors controlling the reinitiation of drug seeking after abstinence. Nebr Symp Motiv 50:197-234.

Sun P, Enslen H, Myung PS, Maurer RA (1994) Differential activation of CREB by $\mathrm{Ca} 2+/$ calmodulin-dependent protein kinases type II and type IV involves phosphorylation of a site that negatively regulates activity. Genes Dev 8:2527-2539.

Suto N, Tanabe LM, Austin JD, Creekmore E, Pham CT, Vezina P (2004) Previous exposure to psychostimulants enhances the reinstatement of cocaine seeking by nucleus accumbens AMPA. Neuropsychopharmacology 29:2149-2159.

Sutton MA, Schmidt EF, Choi KH, Schad CA, Whisler K, Simmons D, Karanian DA, Monteggia LM, Neve RL, Self DW (2003) Extinction-induced upregulation in AMPA receptors reduces cocaine-seeking behaviour. $\mathrm{Na}$ ture 421:70-75.

Taha SA, Fields HL (2006) Inhibitions of nucleus accumbens neurons encode a gating signal for reward-directed behavior. J Neurosci 26:217-222.

Thomas MJ, Beurrier C, Bonci A, Malenka RC (2001) Long-term depression in the nucleus accumbens: a neural correlate of behavioral sensitization to cocaine. Nat Neurosci 4:1217-1223.

Vacher H, Diochot S, Bougis PE, Martin-Eauclaire MF, Mourre C (2006) $\mathrm{Kv} 4$ channels sensitive to BmTX3 in rat nervous system: autoradiographic analysis of their distribution during brain ontogenesis. Eur J Neurosci 24:1325-1340.

Varga AW, Anderson AE, Adams JP, Vogel H, Sweatt JD (2000) Inputspecific immunolocalization of differentially phosphorylated Kv4.2 in the mouse brain. Learn Mem 7:321-332.

Varga AW, Yuan LL, Anderson AE, Schrader LA, Wu GY, Gatchel JR, Johnston D, Sweatt JD (2004) Calcium-calmodulin-dependent kinase II modulates Kv4.2 channel expression and upregulates neuronal A-type potassium currents. J Neurosci 24:3643-3654.

Wayman GA, Lee YS, Tokumitsu H, Silva AJ, Silva A, Soderling TR (2008) Calmodulin-kinases: modulators of neuronal development and plasticity. Neuron 59:914-931.

Wiltgen BJ, Law M, Ostlund S, Mayford M, Balleine BW (2007) The influence of Pavlovian cues on instrumental performance is mediated by CaMKII activity in the striatum. Eur J Neurosci 25:2491-2497.

Wu X, McMurray CT (2001) Calmodulin kinase II attenuation of gene transcription by preventing cAMP response element-binding protein (CREB) dimerization and binding of the CREB-binding protein. J Biol Chem 276:1735-1741. 